\title{
ARTIGOS
}

\author{
Submetido 01.06.2020 Aprovado 02.02.2021
}

Avaliado pelo sistema double blind review. Editora Científica: Leticia Casotti

Versão original | DOI: http://dx.doi.org/10.1590/S0034-759020220203

\section{ELABORAÇÃO (EST)ÉTICA DE FÃS: POACHING COMO PRÁTICA DE VERDADEIRO AMOR}

\author{
Fans' (esth)et(h)ics elaboration: Poaching as true love practice \\ Elaboración est(ética) de fanes: Poaching como verdadero amor
}

Thiago lanatoni Camargo1 | ianatoni@gmail.com | ORCID: 0000-0003-4371-0822

André Luiz Maranhão de Souza-Leão ${ }^{1}$ | andre.sleao@ufpe.br | ORCID: 0000-0002-7660-5845

Bruno Melo Moura1 | brunomtop@gmail.com | ORCID: 0000-0002-8205-4576

1Universidade Federal de Pernambuco, Programa de Pós-Graduação em Administração, Recife, PE, Brasil

\section{RESUMO}

O presente estudo toma a subcultura de fãs como seio de um consumidor produtivo e assume o consumo como prática subjetivadora, baseado na teoria foucaultiana que define a subjetividade como resultado de uma elaboração ética e estética. Com isso, o objetivo do estudo é analisar como fãs elaboram uma (est)ética fânica por meio de posicionamentos de si em relação a produtos de mídia em suas interações. Para tal, analisamos a principal comunidade de fãs da série de TV Game of Thrones (GoT), que se tornou um grande fenômeno de mídia. A genealogia do sujeito foi método adotado para a análise dos comentários de fãs sobre a saga. Os resultados apontam duas formas-sujeito: curtidores e guardiões. Elas se sustentam em estilizações morais que modulam a relação dos fãs com o produto de mídia por meio de uma única ética, a qual interpretamos como poaching, uma "caça” por diferentes prazeres advindos do consumo. Propomos que esse processo revele o que Foucault denomina verdadeiro amor, uma completude de si na relação com o outro.

PALAVRAS-CHAVE | Game of Thrones, subjetividade, genealogia, Foucault, Consumer Culture Theory.

\section{ABSTRACT}

The current study takes the subculture of fans as being the core of productive consumers, and assumes consumption to be a subjectivation practice based on Foucault's theory, which defines subjectivity as the result of an ethical and aesthetic elaboration process. The aim of this study is to analyze how fans elaborate fannish (est)et(h)ics by positioning themselves about media products during their interactions. In order to do so, the main fan community of the TV series "Game of Thrones" (GoT), a major media phenomenon, was analyzed. The genealogy of the subject was the method adopted for analyzing fans' comments about the saga. Results pointed towards two subject-forms, namely likers and guardians. They are based on moral stylizations that modulate fans' relationships with media products through a single ethics, which was interpreted as poaching the different pleasures that arise from consumption. The study's suggestion is that this process reveals what Foucault calls true love, which corresponds to the completeness of self in its relationship with the other.

KEYWORDS / Game of Thrones, subjectivity, genealogy, Foucault, Consumer Culture Theory.

\section{RESUMEN}

Tomando la subcultura de los fanes como el seno de un consumidor productivo y asumiendo que el consumo es una práctica subjetivante, nos anclamos en la teoría de Foucault, que define la subjetividad como el resultado de una elaboración ética y estética. Así, el presente estudio analiza cómo los fanes elaboran una (est)ética fandomera a través de posiciones en relación con productos de medios en sus interacciones. Para ello, examinamos la principal comunidad de fanes de Game of Thrones (GoT), que se ha convertido en un importante fenómeno mediático. El método utilizado es la genealogía del sujeto. Con este fin, analizamos los comentarios de los fanes acerca de la saga. Los resultados apuntan a dos formas temáticas: likers apreciadores y guardianes. Se basan en estilizaciones morales que modulan la relación de los fanes con el producto de los medios a través de una ética única, que interpretamos como caza furtiva, una "caza" de diferentes placeres derivados del consumo. Proponemos que este proceso revela lo que Foucault llama amor verdadero, una completitud de sí mismo en la relación con el otro.

PALABRAS CLAVE I Game of Thrones, subjetividad, genealogía, Foucault, Consumer Culture Theory. 


\section{INTRODUÇÃO}

Recentemente, os estudos da Consumer Culture Theory (CCT) têm ampliado seu entendimento acerca dos contextos culturais que são constituídos por meio de interações mercadológicas (Arnould \& Thompson, 2015; Denegri-Knott, Nixon, \& Abraham, 2018). É o caso das investigações que tratam da subcultura de consumo de fãs (Chen, 2021; Fuschillo, 2017). Esses consumidores são caracterizados pela forma proativa e especializada com que atuam, de modo a serem produtivos em relação tanto aos objetos culturais que consomem quanto ao contexto de cultura participativa em que estão inseridos (Guschwan, 2012; Jenkins, 2006).

Principalmente graças aos avanços tecnológicos e sociais propiciados pela Web 2.0, os fãs têm convergido para espaços sociais em que se reúnem e interagem com seus pares. Essas interações têm por intuito tratar da intensa relação de consumo com objetos midiáticos associados à cultura pop (Fuschillo, 2017; Jenkins, 2015). Como uma intensa relação de consumo, muitas vezes, funciona como força transgressora, possibilita ao consumidor um aprimoramento contínuo de si (Beighton, 2017; Ritzer, 2014).

Tal aprimoramento de si por meio do consumo funciona, simultaneamente, como estética e ética. A estética está presente na novidade dos prazeres experienciados; a ética, na autoatualização emanada por questionamento de projetos, relações ou preocupações existentes por novos horizontes de oportunidades (Jantzen, Fitchett, Østergaard, \& Vetner, 2012). Para Michel Foucault, estética e ética são conceitos sobrepostos: a condição ética é manifestada por meio práticas morais esteticamente materializadas. Assim, o senso estético tem valor ético e é tanto uma preocupação consigo quanto uma relação que alcança o outro, quando constituímos uma imagem moral de nós mesmos para nos posicionarmos diante de alteridades sociais (Foucault, 2004).

Ética é o tema do ciclo ulterior foucaultiano, que se debruça nos processos de subjetivação elaborados por uma gama de práticas e elementos que formulam o sujeito a partir da negociação de verdades socialmente estabelecidas (Foucault, 2016). Quando nos associamos a diferentes contextos sociais, executamos práticas de si que não são limitadas a nós mesmos: os sujeitos exercem uma atividade que impacta a constituição de si e dos outros (Foucault, 2020c). As práticas de si são uma condução aparentemente adequada para o exercício da liberdade presente na jornada de um ser ético. Tal exercício de liberdade nos permite adotar regras e valores morais que emanam da relação que estabelecemos com diferentes verdades presentes em nossa existência (Foucault, 2010, 2020b).

Pautada no entendimento de que os conceitos de Michel Foucault permitem interpretar e compreender noções éticas manifestadas em práticas como o consumo (ver Arnould \& Thompson, 2015; Mikkonen, Moisander, \& Firat, 2011), a presente pesquisa tem como objetivo analisar como fãs elaboram uma (est)ética fânica por meio de posicionamentos em relação a produtos de mídia em suas interações.

Para investigar tal fenômeno, debruçamo-nos sobre a comunidade de fãs Westeros.org, o principal fórum de informações, notícias e discussões de um dos grandes acontecimentos recentes da cultura pop: a série televisiva Game of Thrones (GoT) (Sarikakis, Krug, \& Rodriguez-Amat, 2017; Young, 2014). Lançada em 2011, GoT foi amplamente divulgada como a adaptação televisiva de uma renomada saga literária criada por George R. R. Martin (GRRM): A Song of Ice and Fire (ASolaF) (Fathallah, 2015; Young, 2014). Caracterizada por uma narrativa singular, que combina vários gêneros distintos (e.g., ação, aventura, discussões políticas), o universo ficcional ganhou, na linguagem e estética da TV por assinatura (e.g., efeitos especiais, exposição à violência e à sexualidade), um meio para se tornar um dos maiores fenômenos da indústria do entretenimento do século XXI (MacNeill, 2017; Wells-Lassagne, 2013). Ao longo de suas oito temporadas, exibidas entre 2011 e 
2019, GoT acumulou vários recordes econômicos (e.g., faturamento, gastos por episódios) (Clark, 2019; Maas, 2019; Spanò, 2016) e culturais, com constante reconhecimento em críticas favoráveis e prêmios conquistados (i.e., Emmys), número inéditos de sintonização global simultânea e pirataria executados pela audiência (Sarikakis et al., 2017), entre outros. O universo criado por GRRM e sua transmidiação na forma de série televisiva foi tão impactante que levou fãs da saga a transitarem entre o consumo desses diferentes produtos e se engajarem em comunidades on-line em busca de novos conteúdos e ampliação de suas experiências sobre e com a saga (Fathallah, 2015; MacNeill, 2017).

O trabalho busca expandir a discussões sobre manifestações de subjetividade exploradas pelo campo da CCT (vide Coskuner-Balli, 2020; Jantzen et al., 2012; Thompson, Henry, \& Bardhi, 2018). Por outro lado, apresenta como o estudo de fãs, enquanto área de conhecimento interdisciplinar, contempla possibilidades para o entendimento de novas relações de consumo para o campo da pesquisa do consumidor (Fuschillo, 2017; Guschwan, 2012). Assim, a investigação propõe-se a contribuir para estudos da CCT que se esforçam em combinar e expandir as discussões de estudos culturais. No caso das interações de fãs, consideramos que se trata de um meio para produzir experiências subjetivas (Booth, 2015) as quais, no contexto mercadológico, revelam como subculturas de consumo produzem ethos compartilhados (Fyrberg-Yngfalk, Cova, Pace, \& Skålén, 2014; Schouten \& McAlexander, 1995).

Para tanto, nossa pesquisa foi construída numa trajetória semi-indutiva, materializada na forma como o aporte teórico é adotado. Nas próximas seções, partiremos da teoria foucaultiana da subjetividade e, em diálogo interdisciplinar com o campo de pesquisa (i.e., CCT), articulando como interações de consumo possibilitam o exercício da fanidade. Em seguida, apresentamos a abordagem teórico-metodológica concebida por Foucault para a investigação da subjetivação ética (i.e., genealogia do sujeito ético). Por fim, após apresentar e explorar os resultados, retomamos aos conceitos estabelecidos na revisão de literatura para ampliar a discussão e propor novos insights a partir dos nossos achados. Neste sentido, buscamos racionalizar e contribuir sobre estudos que tratam do fenômeno investigado.

\section{SUBJETIVIDADE NA TEORIA FOUCAULTIANA}

Segundo Foucault (2016), em meio à relação com regras e condutas sociais, os indivíduos deparam-se como um processo por meio do qual produzem a si mesmos enquanto sujeitos. A partir de decisões que compreendem práticas associadas a regras e valores, mas também às necessidades de cada um, é elaborada uma condução aparentemente adequada para se constituírem subjetividades.

A subjetividade é manifestada no compartilhamento presente das formas como nos relacionamos com nós mesmos e com os outros e por meio das quais podemos organizar e fundar a nossa existência (Foucault, 2020c). Para produzir uma subjetividade, Foucault (2020b) destaca que existem certos critérios a serem seguidos, que se sobrepõem e se afetam mutuamente. Cada indivíduo deve constituir para si uma substância ética para que, simultaneamente, atenda os desejos individuais e as normas morais que se fazem presentes em sua vida. É a forma como nos relacionamos com tais normas que nos possibilita compreender os modos de sujeição que nos tornam quem somos. Já a maneira como, em equilíbrio, seguimos essas normas e realizamos nossos desejos materializa-se como atividades realizadas sobre si e para si, que também pode ser entendida como a elaboração do trabalho ético. Assim, estamos executando uma trajetória em que visamos nos consti- 
tuir como sujeitos éticos, algo que só é possível pela produção de uma teleologia do sujeito moral: a relação que estabelecemos com as verdades que estão presentes tanto nos nossos desejos quanto nas normas que seguimos em nossa existência.

Esse processo é pautado pela noção de verdade, que diz respeito aos saberes que compreendem as percepções de si e dos outros (Foucault, 2016). A verdade refere-se a saberes móveis, que não residem em ninguém em particular, mas em cada um, como construções sociais que conduzem à própria existência. Nesse processo, diferentes verdades são simultaneamente influentes sobre e influenciadas por verdades alheias, por meio de um amálgama de saberes (Foucault, 2010).

Na constituição da subjetividade, jogos de verdade permeiam relações de poder. Para Foucault (2020a), o exercício de poder é uma força produtiva inerente às relações sociais e embasa a maneira como somos governados e nos governamos, em um processo contínuo de subjetivação, elaborado em exercícios de liberdade. Esses exercícios são alicerçados na adoção de práticas morais adequadas para si e que servem de referência na relação com os outros. Assim, a liberdade do sujeito está justamente situada na negociação entre as vontades dos indivíduos e a moral socialmente definida.

Esse processo ocorre por meio de técnicas de si, que indicam como os sujeitos operam modificações sobre si mesmos (e.g., seus corpos, seus pensamentos) que, por consequência, impactam as condutas que assumem para si e para os outros. São operações que se configuram em meio a uma dinâmica ampla de desempenho de diferentes práticas sociais (Foucault, 2020c). Assim, essas técnicas perpassam uma dimensão ética que produz os sujeitos. Por ética, Foucault (2020b) refere-se à prática de condutas alinhadas a fundamentos morais da vida social. Tais fundamentos não são dotados como uma imposição exterior, mas como uma constituição formulada por si e para si.

O sujeito, portanto, constrói-se na vontade que há em si, mas pautado pelas verdades que emanam dos fundamentos morais que lhe são apresentados. É justamente por meio dessas verdades que é possível ao sujeito empreender um trabalho ético por meio da prática de um conjunto de técnicas de si (Foucault, 2010). Essas práticas vinculam sujeito e verdade, propiciando o estabelecimento de posicionamentos sociais reflexivos (Foucault, 2020c).

Foucault $(2004,2010,2020 b)$ apresenta a estética como fundamento da ética. Quando se busca uma forma e sentido adequado para a própria existência, noções estéticas estão presentes no que guia as práticas para formular a si mesmo. As práticas de si contemplam um estilo de vida como arte; uma possibilidade de se constituir como ser em uma existência bela. Denominada estética da existência, a jornada etérea em que constituímos quem somos compreende a sobreposição de verdades. Estas estabelecem as condições para o reconhecimento de si. É um processo que indica a vigilância constante de nós mesmos, à medida que negociamos maneiras de atender aos desejos individuais e às normas que regulam nossa existência (Foucault, 2004, 2010).

Nesse sentido, alinhamo-nos aos trabalhos que fazem uso das contribuições foucaultianas como lente teórica para refletir sobre investigações empíricas da CCT (Mikkonen et al., 2011; Thompson et al., 2018). Especificamente, consideramos válido explorar como o contexto mercadológico permite aos consumidores aprimorarem a si de modo a constituírem sua própria subjetividade (Ashman, Patterson, \& Brown, 2018; Thompson \& Kumar, 2021) e proporem uma ética para si (Coskuner-Balli, 2020; Mikkonen \& Badje, 2013). 


\section{FANIDADE: UMA SUBJETIVIDADE DE CONSUMIDORES}

0 contexto mercadológico apresenta certas narrativas que funcionam como regimes de verdade para os consumidores, o que torna os fenômenos investigados pela CCT capazes de determinar posicionamentos éticos e antiéticos aos indivíduos (Coskuner-Balli, 2020; Mikkonen \& Badje, 2013). De modo similar, a forma como consumidores, cada vez mais, se engajam sobre os objetos que consomem espontaneamente pode ser compreendida como uma manifestação da subjetividade foucaultiana (Ashman et al., 2018; Thompson \& Kumar, 2021). Nesse entendimento, as manifestações subjetivas dos consumidores também podem gerar estigmatização dos indivíduos, precipitar tensões sociais interpessoais ou até questionamento da legitimidade de certos movimentos culturais (Coskuner-Balli, 2020; Thompson et al., 2018). Não à toa, essas posições subjetivas exercidas por consumidores têm sido abordadas por investigações da CCT como uma extrapolação ou justaposição de manifestações identitária (Mikkonen et al., 2011; Thompson et al., 2018).

Se o consumo pode ser entendido como uma prática social identitariamente demarcada, o consumidor posiciona sua identidade por meio de alteridade, ao comparar suas práticas àquelas das comunidades em que se insere e da sociedade como um todo (Jantzen et al., 2012; Schau, Muñiz, \& Arnould, 2009). Entre as identidades de consumo, a dos fãs destaca-se por fundar-se em práticas que expressam, simultaneamente, posicionamentos políticos e uma intensa relação com o produto de mídia consumido (Souza-Leão \& Moura, 2018; Booth, 2018).

0 entendimento acerca dos fãs tem sido atrelado ao contexto da cultura participativa, que proporcionou uma mudança na maneira como as pessoas interagem por meio dos diferentes recursos tecnológicos disponíveis e da convergência das mídias, que propiciam o compartilhamento de conteúdos, os quais são os recursos necessários para se estabelecerem experiências interacionais acerca da indústria do entretenimento (Guschwan, 2012; Jenkins, 2006).

As interações entre fãs possibilitam o exercício de práticas criativas e colaborativas, tipicamente transcorridas em comunidades conhecidas como fandoms. Esses agrupamentos são espaços sociais que funcionam como subculturas particulares, com articulação própria, que se fundamenta no apego ao consumo demonstrada pelos produtos de mídia e pelos membros da comunidade (Moura \& Souza-Leão, 2020; Schau et al., 2009). Os fandoms são, portanto, comunidades de consumo estabelecidas pelo cuidado e apego mútuo entre fãs e o objeto consumido que os une (Gushwan, 2012; Moura \& Souza-Leão, 2020).

A fanidade expressa-se no interesse dos fãs por criar conteúdos sobre esses produtos de mídia (Fathallah, 2016; Jenkins, 2015), quando eles se motivam a expandir sua relação com o que consomem e com aqueles que também o consomem (Booth, 2010). Tais conteúdos são denominados produções de fãs (e.g., fan fictions, fan blogs, fan videos, fan wikis). Nos fandoms, essas produções são experiências particulares, visando os interesses comuns que os fãs compartilham em torno de produtos de mídia (Booth, 2010; Guschwan, 2012).

Diante disso, é possível dizer que a constituição de subjetividade dos fãs perpassa suas interações em relação aos produtos de mídia. Suas práticas centralizam esses produtos como corpo de saberes que norteia suas condutas (Chen, 2021; Souza-Leão \& Moura, 2018), saberes esses que são responsáveis por impulsionar 0 acesso dos fãs aos recursos com os quais se socializam e se relacionam (Fuschillo, 2017). 


\section{PROCEDIMENTOS METODOLÓGICOS}

Em aderência ao lastro teórico foucaultiano, adotamos a Genealogia do Sujeito Ético como estratégia metodológica. Trata-se de uma abordagem qualitativa de matriz pós-estruturalista, posicionamento de pesquisa emergente no campo da CCT (Arnould \& Thompson, 2015). 0 método foi proposto por Michel Foucault como meio para entender como os sujeitos se constituem a partir das relações de saber e poder, por meio de práticas de si (Foucault, 2020b), sendo um desdobramento de sua Genealogia do Poder.

Para Foucault (2016), o que chamamos de moral é o comportamento efetivo das pessoas. Assim, é por meio de suas condutas que os indivíduos se tornam sujeitos, sendo a subjetividade uma forma que, por sua vez, revela uma ética. Como meio para se identificarem tais formas-sujeito, Foucault (2020b) estabelece critérios que denominou agentes morais, os quais se fundamentam em seu desenvolvimento teórico acerca dos processos de subjetivação (vide Quadro 1).

Quadro 1. Quadro 1. Descrição dos agentes morais

\begin{tabular}{l|l}
\hline Categoria & Definição \\
\hline $\begin{array}{l}\text { Substância } \\
\text { ética }\end{array}$ & $\begin{array}{l}\text { Trata-se da maneira pela qual o indivíduo deve constituir parte de si como matéria principal de sua conduta } \\
\text { moral. Pode dar-se por meio do domínio de seus desejos, do respeito às interdições e obrigações em suas } \\
\text { próprias ações, da continuidade e reciprocidade dos sentimentos que se experimenta pelo outro. }\end{array}$ \\
\hline $\begin{array}{l}\text { Modos de } \\
\text { sujeição }\end{array}$ & $\begin{array}{l}\text { Diz respeito à maneira pela qual os indivíduos se relacionam com regras morais e se reconhecem como } \\
\text { obrigados a pô-las em prática. Pode dar-se por meio da adesão ou submissão a certos princípios e } \\
\text { comportamentos de grupos ou comunidades de que fazem parte, pelo entendimento de que se pertença a } \\
\text { certa tradição que deve ser preservada e/ou revivida, pela resposta a apelos que deem forma (estética) à vida } \\
\text { pessoal. }\end{array}$ \\
\hline $\begin{array}{l}\text { Elaboração do } \\
\text { trabalho ético }\end{array}$ & $\begin{array}{l}\text { Trata-se da atividade realizada sobre si mesmo de modo a tornar sua conduta conforme as regras e valores } \\
\text { morais. Pode dar-se por meio de um trabalho de aprendizagem dos princípios de uma regra moral, da } \\
\text { avaliação da conduta em relação à sua aderência à regra a qual segue, da renúncia aos prazeres, da } \\
\text { decifração dos movimentos do desejo. }\end{array}$ \\
\hline $\begin{array}{l}\text { Teleologia do } \\
\text { sujeito moral }\end{array}$ & $\begin{array}{l}\text { Diz respeito à busca por constituir-se como certo sujeito moral particular. Pode-se aspirar várias } \\
\text { subjetividades morais possíveis: ser puro ou honrado em relação a certos códigos, fazer-se liberto de certos } \\
\text { juízos ou tradições, tornar-se expert em certa prática. }\end{array}$ \\
Fonte: Adaptado de Foucault (2020b).
\end{tabular}

Sendo fundamentados nas relações de poder e saber, a análise desses agentes morais embasa-se na identificação de diagramas de poder, que dizem respeito à relação entre práticas discursivas (i.e., saber) e não discursivas (i.e., poder acrescido ao saber), que leva a uma configuração denominada por Foucault (2020a) dispositivo e articula como certos domínios de saberes fundamentam exercícios de poder. Segundo Deleuze (1988), isso reflete como a trajetória filosófica foucaultiana sempre tratou de um tema ulterior, uma investigação de como se constituem os sujeitos éticos. Essa constituição só é possível a partir das formas de governo e relações de poder (i.e., diagramas) que se fazem presentes na vida dos sujeitos; num movimento similar, não existem relações de poder sem a constituição de um campo de saber, assim como não há saber que não formule ou não suponha, simultaneamente, diagramas de poder; estes, por consequência, não existem sem que constituam arenas sociais como possibilidade à produção de subjetividades. É assim que éticas se tornam eliciáveis por meio do processo que revela formas-sujeitos decorrentes de agentes morais fundamentados em diagramas de poder (Foucault, 2016, 2020c). A partir desses direcionamentos, podemos sistematizar o método analítico segundo as etapas representadas na Figura 1. 


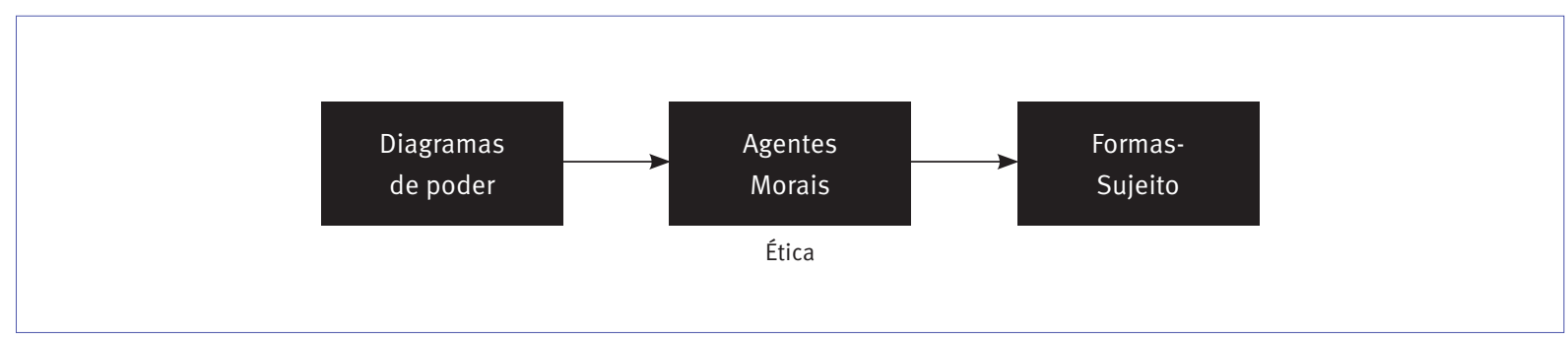

Fonte: Adaptado de Foucault (2016, 2020b).

Assim, a Genealogia do Sujeito Ético debruça-se sobre três camadas de práticas (ver Figura 1): as práticas discursivas (i.e., o que se diz), a respeito de um dado fenômeno, que ocorrem em meio a um contexto de práticas não discursivas (i.e., relações diretas e indiretas de poder), que norteiam práticas de si (i.e., condutas) (Foucault, 2020b). Uma vez que a análise de discurso - tradição em que se insere a abordagem metodológica de Foucault - se revela por meio de texto e contexto, do dito e não dito, tais camadas podem ser acessíveis por meio dos mesmos textos. De fato, o corpus filosófico foucaultiano foi integralmente construído sobre a análise de fontes documentais.

Para a presente investigação, adotamos como dado interações de fãs de ASolaF na Westeros.org, principal fórum virtual sobre o universo ficcional, que concentra o maior fandom da obra de GRRM (Young, 2014). 0 site é organizado em seções que se debruçam sobre vários temas de discussão na forma de textos publicados pelos participantes. Para a pesquisa, coletamos as discussões de fãs que se referem a cada um dos episódios de GoT, disponíveis como um dos conteúdos específicos da comunidade virtual. Foram baixados e arquivados todos os tópicos e comentários referente aos 73 episódios da série, num total de 19.660 mensagens, postadas no período de 2011 a 2019, correspondente à transmissão da série. Os dados foram analisados em sequência cronológica de publicação, de modo a apreendermos o contexto produtivo das interações representadas nas mensagens postadas, bem como vislumbrarmos as mudanças em andamento ao longo do tempo nas práticas (i.e., discursivas, não discursivas e de si) dos fãs.

\section{DESCRIÇÃO E DISCUSSÃO DOS RESULTADOS}

A seção organiza-se por meio das quatro categorias do processo analítico, as três primeiras referentes às categorias de análise propriamente ditas, enquanto a quarta corresponde ao resultado do procedimento (vide Figura 1). A Figura 2 apresenta o resultado desse processo. Os diagramas de poder são apresentados de maneira descritiva, evocando os contextos empíricos nos quais foram identificados. Na mesma linha, os agentes morais contam, ainda, com a apresentação de seus critérios constitutivos. Para descrever as formas-sujeito e, de maneira retroativa, as categorias analíticas que lhes dão alicerce, recorremos a exemplos empíricos, em tradução livre dos originais em inglês. Sua função é de ilustrar não apenas a categoria ulterior, mas os feixes completos de análise (i.e., diagramas de poder - agentes morais - formas-sujeito). Por fim, a ética eliciada desse processo é discutida à luz de um retorno à teoria. 
Figura 2. Configuração das categorias analíticas

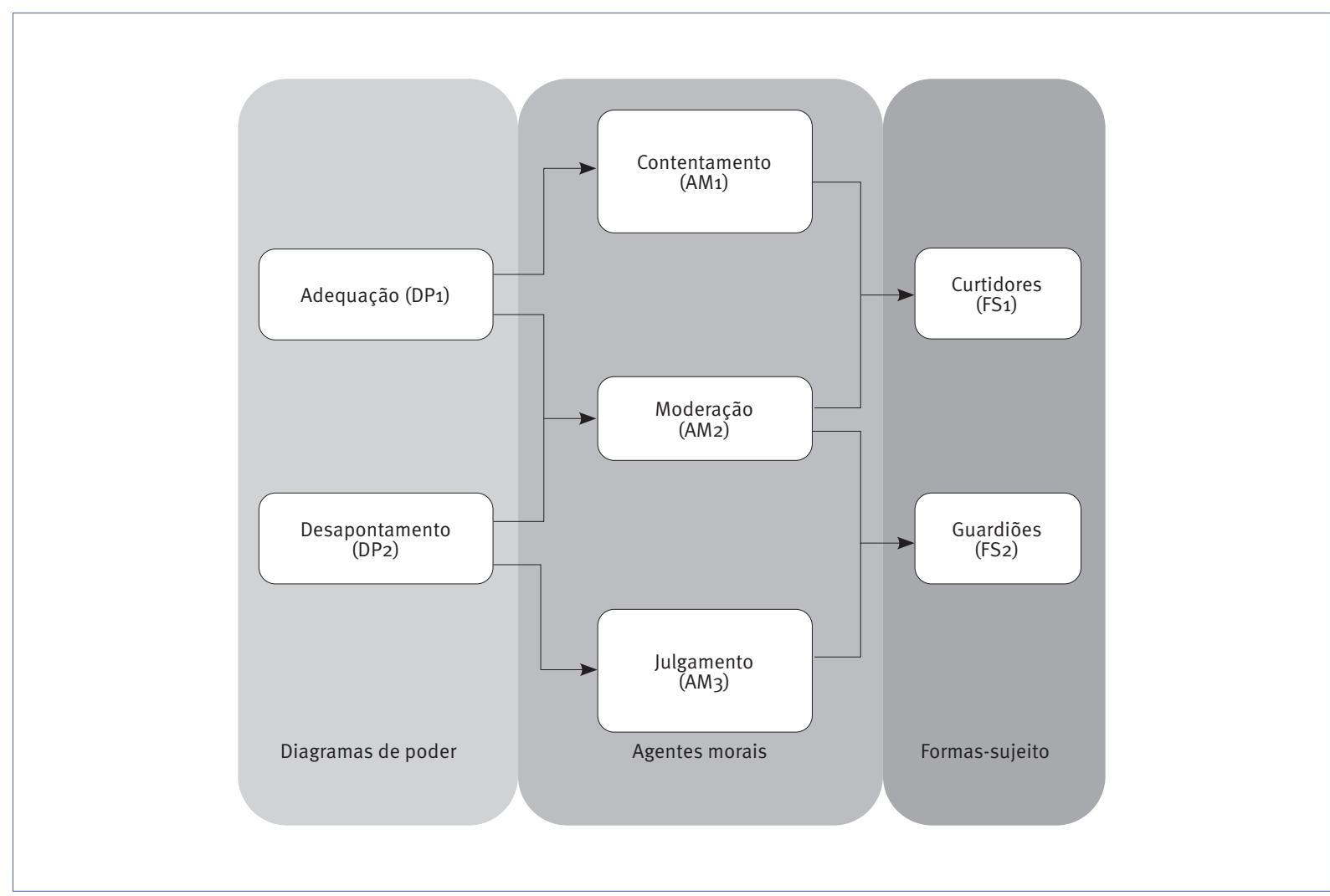

\section{Diagramas de poder}

Identificamos dois diagramas de poder nos dados analisados. Apesar de díspares, não são opostos. 0 primeiro deles aponta para elogios à série televisiva, o qual denominamos adequação (DP1). Nesse diagrama, os fãs consideram que existe uma autonomia da linguagem televisiva capaz de contribuir para o universo ficcional. A série é valorizada por catalisar uma expansão da apresentação da saga, tanto pela complementação de seu conteúdo quanto por meio de recursos sensoriais não possibilitados pelos livros.

Isso é atestado como resultado da qualidade técnica da produção (e.g., escolha de elenco, efeitos especiais), do preenchimento de lacunas da narrativa que teriam sido omitidas nos livros e, principalmente, pela materialização para uma mídia de massa de um enredo complexo e cheio de reviravoltas. Nesse sentido, é entendido que GoT apresenta o universo ficcional a um novo público, resultando em um aumento da base de fãs da ASolaF e no crescimento do fandom, o que intensifica e facilita possibilidades de interação entre fãs. Por outro lado, a forma como a série é conduzida permite uma reinterpretação da saga para os leitores da obra literária, expandindo a experiência de sua fruição.

0 segundo diagrama designamos desapontamento (DP2), por refletir as críticas à forma como o universo ficcional foi apropriado pela televisão. A partir de uma posição em que evocam o próprio conhecimento do universo ficcional adquirido pela leitura do conteúdo original, fãs argumentam que a série não respeita o cânone estabelecido nos livros, uma vez que incorre em mudanças que consideram em desconformidade com o que é construído na narrativa original. 
Tal aspecto aparece em vários argumentos: de que o papel de personagens secundários é desconsiderado; de que as questões políticas e filosóficas presentes na obra são tratadas de modo superficial; de que aspectos geográficos do mundo ficcional são pormenorizados; e de que a dimensão sobrenatural é colocada em segundo plano. Esses problemas são entendidos como mais evidentes à medida que GoT ultrapassa o conteúdo dos livros publicados; fãs se frustram com a conclusão da série e não aceitam que ela seja o desfecho adequado da trama

- inclusive atacando GRRM por não ter concluído os dois últimos livros planejados e até receosos de que isso não venha a acontecer, dada a idade avançada do autor.

Apesar de evidenciarem uma concepção oposta em relação a GoT, esses diagramas não são evidenciados de modo radical: a legitimidade da tradução que a série televisiva faz da obra literária (DP1) transcorre por meio de elogios empolgados a reconhecimentos mais sóbrios; de modo semelhante, o descontentamento com a forma como essa transposição é feita (DP2) vai de ataques agudos a críticas ponderadas. Esse limiar fica evidente quando as características das mídias são confrontadas: uma valorização menos eufórica da série reconhece que ela é uma boa tradução da obra se se levarem em consideração as particularidades da linguagem televisiva; nessa linha, uma crítica não contumaz argumenta que essa linguagem não justifica a exclusão de pontos cruciais da saga.

Por outro lado, esses diagramas encontram-se no referencial que assumem. Embora a partir de pontos de vista distintos, eles comungam do efeito que a adaptação televisiva trouxe para a saga; são movimentos fânicos que, em tons distintos, refletem acerca da existência da série televisiva em relação a como o cânone do universo ficcional é traduzido por meio de outra mídia.

\section{Agentes morais}

Uma vez que a moral como aqui tratada reflete as formas como os sujeitos se posicionam em relação à construção de diferentes verdades, a dinâmica existente entre os dois diagramas de poder apresentados evidenciou três agentes morais na pesquisa. Dois deles, mais alinhados singularmente a cada um dos diagramas, apontam para formas distintas, mas não disjuntas, de se enxergar a adaptação televisiva de ASolaF. O outro se apresenta nesse limiar de contundência com que essa relação se constitui.

Assim, evidenciamos um sentimento de contentamento ( $\left.A M_{1}\right)$ entre fãs que assumem que a série contribui para a saga (DP1). Esse agente moral tem como substância ética a concepção da fruição de a adaptação transmidiática propiciar uma experiência hedônica, defendendo a premissa de que ser fã da saga não pode ser limitado ao desejo de uma reprodução fidedigna do conteúdo dos livros. Para parte do fandom, a fanidade para com o universo ficcional também está presente na compreensão da autonomia de cada mídia (teleologia do sujeito moral), que, por sua vez, é capaz de apresentar uma linguagem própria responsável por papel e finalidade distintos na produção da narrativa e no provimento de experiências (modo de sujeição) que definem a fanidade. Assim, esses fãs estão legitimando a experiência (elaboração do trabalho ético) ao destacar a qualidade da série e valorizar seu grande êxito midiático.

Por outro lado, identificamos um julgamento $\left(\mathrm{AM}_{3}\right)$ nos fãs que assumem que a série deveria ser completamente fiel à obra literária sobre a qual se baseia (DP2). Esse agente moral indica como os fãs proclamam a primazia dos valores do cânone (substância ética) e, para isso, atuam de modo a executar sua apregoação (modo de sujeição). Seu intuito é demonstrar que a autenticidade do produto de mídia (teleologia do sujeito moral) é a base para a existência de uma fanidade caracterizada por uma relação comprometida com o objeto consumido. 
Nesse sentido, esses fãs atuam na preservação do cânone (elaboração do trabalho ético), ao evocarem o que consideram ser o fundamento de fidedignidade da obra, buscando assegurar essa base como depositária do conhecimento que define o universo ficcional.

Entre essas posições, uma moderação (AM2) evidencia-se no limiar de compreensão em que se insere o diálogo transmidiático entre os produtos culturais. Esse agente moral reúne uma experiência televisiva hedônica que prima pela fidelidade ao cânone literário (substâncias éticas). Há uma compreensão de que a fanidade deve beneficiar-se da combinação de diferentes linguagens midiáticas (teleologia do sujeito moral) pelas quais a saga se materializa. Assim, os fãs que se pronunciam nessa fronteira performam uma conciliação (modo de sujeição) de diferentes opiniões sobre a série televisiva, inclusive atenuando as suas próprias em prol do entendimento no fandom. Nesse intuito, proclamam o respeito às diferenças (elaboração do trabalho ético), tentando estabelecer o diálogo entre posicionamentos discrepantes sobre a série, incentivando posturas reflexivas na elaboração de opiniões e apoiando novos fãs da comunidade a se adaptarem às discussões.

\section{Formas-sujeito}

As relações entre as categorias analíticas anteriores levaram-nos à percepção da existência de duas formas-sujeito: uma de fãs que aproveitam a expansão da saga para outra mídia e uma de fãs que tomam para si a missão de proteger o cânone do universo ficcional. Elas guardam relação direta com os diagramas de poder, contudo refletem sua modalização, proeminente nos agentes morais. Por consequência, as formas-sujeito identificadas não são antagônicas, mas, simultaneamente, concorrentes e complementares, refletindo posições que negociam legitimidades fânicas acerca de um mesmo produto de mídia.

Curtidores (FS1) é a forma-sujeito dos fãs que potencializam sua relação com a saga por meio da ampliação da vivência hedônicas. Essa fanidade é uma manifestação pautada na diversão, conduzida por meio de uma abertura a diferentes experiências, conforme as potencialidades de mídias distintas. A forma como usufruem (AM1) dessa trasmidiação (DP1) marca a singularidade dessa forma-sujeito. Para ilustrá-la, destacamos a mensagem de um fã da saga após assistir ao terceiro episódio da primeira temporada da série:

Li os livros duas vezes e adoro o trabalho de Martin há anos. Esta série da HBO está rapidamente se tornando meu programa de televisão favorito. A qualidade é tudo o que espero da HBO. O casting está impecável e estou adorando cada minuto [...] o cerne da história, os personagens profundos e completos que amamos e odiamos, estão todos lá. Obrigado, Sr. Martin e HBO. Trabalho bem executado. (Fonte: https://asoiaf.westeros.org/index.php?/topic/49576-poll-how-would-you-rate-episode-103/page/4/ Tradução livre.)

Na fala publicada após assistir o terceiro episódio da primeira temporada da série, o fã aponta como a adaptação dos livros escritos por GRRM para TV tem-se tornado seu programa televisivo favorito. Nesse momento, existiam dois sentimentos predominantes no fandom. Por um lado, a empolgação manifestada desde o anúncio de a transmidiação de ASolaF ser conduzida pela rede de canais HBO - reconhecida na cultura pop por produzir séries televisivas com uma qualidade narrativa acima da média. Por outro, um temor pela forma que um enredo tão complexo como o dos livros criados por GRRM seria apropriado para ser apresentado a um público (i.e., telespectadores) que priorizam o entretenimento ante questões políticas. 
A mensagem expressa a soma dos dois sentimentos presentes no fandom, onde o primeiro (i.e., empolgação) predomina diante do segundo (i.e., temor), muito provavelmente por, naquele momento, este parecer infundado diante da qualidade dos episódios iniciais do programa de TV. Ao permitir revisitar a saga que já admira, o fã considera GoT um deleite para os leitores de ASolaF (AM1), enumerando como a qualidade da série televisiva sobrepõe detalhes que não poderiam ser adaptados dos livros, atestando-a como uma adaptação que os traduz de maneira adequada (DP1).

Por outro lado, temos os fãs que se consideram Guardiões (FS2). Essa forma-sujeito reforça sua relação com o produto de mídia com base na prioridade que dão ao cânone estabelecido no conteúdo original. A fanidade é aqui expressada como lealdade aos fundamentos e detalhes da obra literária, que é estabelecida como verdade canônica. Essa condição é singularizada na satisfação $\left(\mathrm{AM}_{3}\right)$ em se evidenciar as limitações da série em entregar isso (DP2). Tal aspecto é exemplificado por meio da mensagem de um fã que destacamos abaixo:

Então talvez esta série não seja para vocês dois, já que seu prólogo configurou por fazer uso dessa premissa. Nem todo mundo gosta de dragões ou magia, mas eles fazem parte do quadro geral. Estou apenas desapontado que os produtores do show não o encerraram com o fim dos livros, pois afirmam que iriam adaptá-los, mas o que têm feito é um trabalho pobre e tendencioso. Não foi apenas essa omissão. Eu já estou com um pé fora, por assim dizer, e, com o extra do episódio passado, perdi toda a minha confiança nos produtores da série.

(Fonte: https://asoiaf.westeros.org/index.php?/topic/112364-how-would-you-rate-episode-410/page/6/\#comments Tradução livre.)

A percepção do fã sobre o episódio final da quarta temporada contesta o argumento de outro membro do fórum quanto ao uso de um recurso narrativo típico de GRRM (i.e., morte de personagens). Àquela altura, GoT já se consolidara como um dos grandes fenômenos da cultura pop, o que levou a existirem, dentro do fandom de ASolaF, membros que apenas haviam assistido à adaptação para TV da saga.

Nesse sentido, começara-se um movimento de cisma entre fãs do produto cultural - em muito, estimulado por mudanças narrativas operadas na adaptação televisiva que não mais seguia, à risca, o conteúdo dos livros. Tal movimento buscava deslegitimar o conteúdo de GoT para renegar a presença de fãs superficiais - aqueles que nunca leram os livros - no fandom e, consequentemente, elencar como ASolaF era uma obra superior à sua adaptação. No comentário destacado, o fã defende que cada particularidade do cânone, mesmo que não interesse a algumas pessoas, deve ser apreciada, pois é parte de uma grande obra (AM3). Assim, sente-se desencantado com o show, por entender que nem seus produtores, nem sua audiência, parecem compreender a saga (DP2).

Conforme antecipado, essas formas-sujeito sobrepõem-se na busca de se manter a coesão do fandom $(A M 2)$. Isso é feito ao se demonstrar, de maneira reflexiva, seja uma valorização (DP1), seja uma decepção (DP2) com a série. Nos depoimentos, é mais comum observarmos esses movimentos separadamente, o que atesta a moderação em cada forma-sujeito. Por vez, no entanto, isso se evidencia simultaneamente, como é o caso presente da mensagem enviada por um fã sobre o fim da sétima (e penúltima) temporada da série.

Como o último episódio da temporada, devo dizer, este episódio conclui algum arco que parecia se arrastar ou que precisava ser encerrado para que a série pudesse progredir. Prós: [...] honestamente, já se passaram 8 anos e a muralha finalmente caiu. Por alguma razão, quem começou a ler os livros quando começou (anos 90?). Mesmo no programa de TV, deve ser legal e bom vê-lo caindo. Eu só comecei a ler o livro quando o show começou, então para mim não foi uma espera tão grande comparada aos leitores [...]. Contras: [...] a Golden Company agora é o exército mais forte? Realmente? Achei que fosse o Dothraki. Eles têm 20.000? (Fonte: https://asoiaf.westeros.org/index.php?/topic/148147-poll-how-would-you-rate-episode-707/ Tradução livre.) 
A divergência narrativa entre ASolaF e GoT - e a consequente cisma que passou a se fazer presente no fandom - tornou-se cada vez mais latente com o passar do tempo. Por um lado, existia o movimento de fãs em renegar a série televisiva como adaptação da saga literária. Por outro, uma parte do fandom buscava reconhecer como o programa de TV conseguia manter - independentemente da fidedignidade ao conteúdo original - o nível de qualidade inicial do show, mesmo que a partir de outros aspectos inerentes a essa mídia (e.g., atuação do elenco, uso de efeitos especiais). Havia, ainda, aqueles que ficavam em cima de muro, reconhecendo validade nos argumentos de ambos os lados.

Na parte que destacamos da fala desse fã, é possível observar uma excitação de como finalmente o programa parece voltar a progredir, algo que poderia acalmar ânimos distintos do fandom (AM2). Para o fã, é natural que existam, simultaneamente, pontos a serem valorizados (i.e., prós) (DP1) e outros a serem criticados (i.e., contras) (DP2) na forma como uma das temporadas conclusivas do show foi conduzida. Àquela altura dos eventos do universo ficcional apresentados em GoT, a série tanto permite consumir momentos-chave de ASolaF, que há muito eram aguardados e premeditados entre os fãs (DP1), quanto pode comprometer essa experiência de consumo na forma como o enredo é conduzido (DP2).

\section{Ética}

Em consonância com o estatuto estético da ética na teoria foucaultiana, interpretamos nossos achados a partir do que Foucault (2020b) denominou estilizações morais do sujeito - que representam as maneiras pelas quais as pessoas dão forma às suas condutas sociais, por meio do uso dos prazeres. Abaixo, apresentamos uma síntese do que se trata, a partir do que é conbido em Foucault (2020b).

O filósofo começa sua explanação pela dietética, que diz respeito à arte de se relacionar cotidianamente consigo mesmo, delimitando a extensão de seus desejos. Nessa perspectiva, apesar de a realização dos desejos ser entendida como algo natural, pode ultrapassar certos limites se envolver práticas excessivas: fisicamente, dos próprios corpos; e moralmente, por envolver outros. Assim, seguir regimes morais que moderem o usufruto dos prazeres propicia preserva o valor e a imagem de si perante os outros, ao mesmo tempo que estende sua existência. Trata-se, portanto, de uma estilização ôntica, em que o reconhecimento alheio atesta a capacidade de ser de um indivíduo, demandando a necessidade de se governar o próprio corpo para se viver em constante atenção sobre os desejos, manifestados em práticas e relações sociais.

A estilização econômica, por sua vez, diz respeito à condução de si que permita ser capaz de cuidar dos outros, o que é discutido a partir do âmbito familiar até uma extrapolação social mais ampla. Ao incorporar para si valores morais que expressam valores da sociedade em termos mais amplos, o indivíduo assume responsabilidades que se somam às dos outros, em um apoio produtivo para a constituição de cada um como sujeito. Assim, diz respeito a uma estilização de comportamento ideal, visando ao bem comum, que demanda do sujeito um reconhecimento de seu valor moral perante a alteridade social, de modo que possa governar a si e aos outros.

Por fim, a erótica trata-se de um jogo cênico, em que diferentes atores são atraídos pelo que os outros são capazes de lhes propiciar. Representa como as vontades de um sujeito afetam e são afetadas pelas necessidades alheias, numa jornada de prazer mútuo, com o intuito de se firmar uma relação positiva para ambas as partes. Nessa perspectiva, as relações de prazer e as relações sociais de modo geral tornam-se isomórficas, uma vez que convergem liberdades e escolhas em prol do prazer de si e do outro. É uma estilização de compartilha- 
mento, em que não há submissão, dominação ou opressão, mas uma contribuição entre sujeitos que constituem a si mesmos na retribuição mútua de necessidades e desejos.

A partir de tais conceitos foucaultianos, entendemos que o contentamento (AM1) expresse uma erótica na forma como os fãs de ASolaF buscam expandir sua experiência hedônica por meio de GoT. Trata-se de uma liberdade dos fãs presente na manifestação dos prazeres para si e para aqueles com quem se relacionam a partir do consumo de um produto de entretenimento. 0 julgamento $\left(A M_{3}\right)$, por sua vez, reproduz uma lógica da econômica, uma vez que os valores e singularidades do cânone são considerados pelos fãs a fonte de prazer com o produto de mídia. Buscar regular como GoT deveria ser realizado é uma atividade exultante para os fãs de ASolaF, que se sentem responsáveis pela preservação de seu conteúdo. Já a moderação (AM2) assume papel dietético, ao refletir uma busca de equilíbrio entre o prazer em consumir a transmidiação e o cuidado com a saga. Essa conduta moral busca estabilizar as diferenças de perspectivas existentes no fandom, como forma de sua manutenção.

Portanto, os posicionamentos que observamos entre os fãs de ASolaF que os levam a serem concebidos como curtidores (FS1) de GoT apresentam como singularidade uma fanidade fundada na erótica, na busca por experiências hedônicas, por diversão. Em seu clássico trabalho, Hirschman e Holbrook (1982) afirmam que o consumo é uma prática social que extrapola a percepção cognitiva ou utilitarista. Os autores propõem o consumo como uma prática retórica, já que leva os consumidores a exercerem suas capacidades e disposição de ressignificarem para si experiências pessoais na busca por prazer. A experiência hedônica considera que o consumo é uma atividade que pode divertir, emocionar e estabelecer significados particulares. Quando consumir está pautado na diversão, pequenos prazeres pessoais são manifestados diante de uma dinâmica social estabelecida entre e pelos consumidores (Coulter, 2021; Jantzen et al., 2012). No âmbito fânico, a fruição dos produtos de mídia é intrínseca às experiências de consumo, que, por se relacionarem a conteúdos de entretenimento, têm como função unir pessoas que compartilham de práticas sociais e pessoais a partir da busca por diversão (Fathallah, 2016).

Por outro lado, os fãs que assumem o papel de guardiões (FS2) têm por singularidade a fanidade como estilização econômica. Eles atribuem para si uma série de valores e responsabilidades ao produto de mídia, uma relação íntima com este, um sentimento de curadoria. Assim, relacionam-se com o produto de mídia como se colecionassem domínios e saberes que não podem ser profanados. Para Belk (2001), a relação íntima entre consumidor e objeto consumido pode indicar um comportamento de colecionismo quando o consumo não se trata apenas de fazer usufruto do produto, mas de incorporar aspectos deste tanto em formas intensas de manutenção e armazenamento quanto na promulgação da vida cotidiana do colecionador. Ao ser colecionado, o objeto ganha novas concepções para a biografia dos consumidores, estando presente em aspectos de seu cotidiano (Woodward \& Greasley, 2017). Colecionar é uma prática cultural de selecionar artefatos específicos que se dá pela sua importância e significado pessoal, num movimento curatorial (McCracken, 1988). No intuito de expressar e estabelecer seus interesses, os fãs atuam como curadores dos produtos de mídia que consomem (Jenkins, 2007; Ryan, 2015), principalmente porque a forma como os tratam e preservam é um dos poucos questionamentos que podem colocar sua presença no fandom em xeque (Kompare, 2018).

Por fim, há uma conduta dietética comum aos curtidores (FS1) e guardiões (FS2). Essa conduta reflete a fanidade como uma prática social fluida, que envolve conexão emocional e interesse cognitivo pelos produtos de mídia e requer a interação como fundamento. Assim, as distintas opiniões expressas dentro de um mesmo fandom terminam legitimando-se por meio de um respeito às diferenças estabelecido entre seus membros. Kozinets (1999) considera que os membros mais emblemáticos das comunidades de consumo são aqueles que 
equilibram e misturam suas experiências atreladas ao objeto consumido com aspectos sociais, pessoais e relacionais. Apesar de as comunidades de consumo apresentarem membros heterogêneos entre si, funcionam como núcleo da ligação afetiva ou cognitiva de seus membros em relação às suas experiências de consumo. Os fandoms funcionam de modo similar, ao agregarem diferentes posicionamentos acerca de produtos de mídia por meio de sua fruição, ações produtivas e disseminação de informações (Delwiche \& Henderson, 2012; Fuschillo, 2017).

Lidar com diferenças e diversidade tem sido registrado como uma característica da cultura de fãs (Hills, 2013; Kozinets, 2001). É compreensível, portanto, que esse aspecto module as singularidades das formas-sujeito identificadas. Entretanto, antes disso, outro aspecto que caracteriza essa cultura é o entendimento de que a fruição dos produtos de mídia tanto propicie entretenimento quanto provoque engajamento (Chen, 2021; Jenkins, 2006). Assim, curtidores e guardiões revelam-se como posições fânicas que guardam contiguidade. Dessa forma, entendemos que nosso estudo revele uma ética única, produzida na intensa relação que os fãs nutrem com objetos midiáticos atrelados à cultura pop. Essa ética, por sua vez, evidencia-se fundamentada em um ethos da cultura fânica.

Propomos que a ética observada se refere a um poaching. Jenkins (2015) cunhou o termo textual poachers para designar o tipo de relação que fãs estabelecem com os produtos de mídia. 0 autor entende que o consumo dos fãs é um ato imersivo, uma "caça” constante, caracterizada por contínuas releituras dos textos de mídia, a partir de sua adoção como parte de suas experiências de vida e os utilizando como meio de promoção de interações com seus pares. Essa "caça” torna-os nômades, transitando e convergindo entre aspectos da sua vida pessoal e social e os universos ficcionais dos quais se sentem parte.

\section{CONCLUSÃO}

O presente estudo apresenta como o posicionamento de fãs de produtos de mídia, em suas interações, elabora uma ética fânica por meio de estilizações que evidenciam uma dialogia contígua. Ao propormos que essa ética se refira a um poaching, afirmamos que se trata de uma "caça” por diferentes prazeres advindos do consumo de diferentes objetos da cultura pop. 0 poaching revela um processo de subjetivação que exprime a existência de modulações que englobam diferentes formas com que se manifestam as relações do fã com o produto midiático. Trata-se de uma ética que reflete a jornada fânica em que experiências relacionadas ao consumo de um produto de mídia (i.e., curtir, curar e respeitar diferenças) funcionam como caminhos alternativos e contíguos para as formas de problematização de si enquanto fãs da cultura pop.

Se, para Jenkins (2015), o poaching é a principal característica para definir os fãs, nossos achados permitem aprofundar esse entendimento no sentido de que se trata de um processo em que o fã exerce sua fanidade. Assim, argumentamos que o poaching tanto propicia uma intensificação de desejos por meio de relações de consumo quanto produz relações sociais, configurando esses aspectos como inerentes à condição de ser-se fã: com o produto de mídia, por meio de interações com pares em um contexto de comunidade (i.e., o fandom). É a partir dessa concepção que articulamos o conceito de poaching à constituição do sujeito ético foucaultiano. Nesse sentido, evocamos como Deleuze (1988) entende que, para Foucault, um sujeito é, simultaneamente, um ser desejante e um ser social, constituído a partir de relações com as verdades que se fazem presentes em sua existência.

Sobre a relação com as verdades, Foucault (2020b) descreve as estilizações morais como um caminho para se encontrar a verdade por meio do outro, na forma do amor. Em meio à negociação de liberdades e verdades, o 
verdadeiro amor é estabelecível na combinação do zelo de si e dos outros (i.e., dietética), do cuidado de si e dos outros (i.e., econômica) e do prazer para si e para os outros (i.e., erótica). O filósofo argumenta que, no verdadeiro amor corpo e alma, não são esferas aditivas, mas uma instância unificadora de conhecimento dos corpos e partilha das almas, que propicia a completude de si na relação com o outro. O verdadeiro amor é, de modo ulterior, uma possibilidade de estabelecimento de uma condição existencial do sujeito ético: ao compartilhar seus desejos e sentimentos, expressa-se como um ser desejante; ao estabelecer fidelidade e um papel produtivo para a sociedade, legitima-se como um ser social; ao preservar a si próprio e manter-se fiel consigo mesmo, constitui-se como ser moral (Foucault, 2020b). É por meio dessa articulação teórica que concebemos o poaching como verdadeiro amor em relação ao ser fã como sujeito ético, estabelecido na relação de prazer corpóreo e realização espiritual com o produto de mídia, por meio de suas interações com pares em um contexto de coletividade. Por consequência, entendemos que essa relação de verdadeiro amor é intrínseca à concepção ética fânica na negociação de verdades internas e externas relacionadas ao objeto consumido. Essas verdades, segundo Foucault (2020a), permitem-nos depararmos com nossa própria existência; ao se negociarem diferentes formas de lidar com verdades, é possível se alcançarem modos de subjetivação que fazem parte da jornada ética em que nos constituímos como sujeitos morais.

Assim, nossos resultados alinham-se ao entendimento de que o consumo é uma prática social que permite manifestações de subjetividade como conduções éticas (ver Denegri-Knott, et al., 2018; Jantzen et al., 2012). Especificamente, as subjetividades manifestadas pela intensa relação dos fãs com produtos de mídia revela-se como possibilidades de emancipações mercadológicas e sociais (Chen, 2021; Souza-Leão \& Moura, 2018).

Por outro lado, a presente investigação traz uma discussão que combina elementos apresentados em discussões de estudos culturais (Booth, 2015) e de pesquisas do consumidor (Schouten \& McAlexander, 1995), de modo a expandir o entendimento de como práticas culturais e interacionais, como o consumo especializado dos fãs, produzem verdades que constituem éticas do sujeito contemporâneo. Assim, credita a interdisciplinaridade entre estudo de fãs e pesquisa do consumidor, seja pelo seu aspecto econômico e cultural (i.e., relação íntima com a indústria do entretenimento e a cultura pop), seja por permitir explorar o consumo como prática de subjetivação.

De maneira específica, ao fazer uso das concepções de Michel Foucault para fundar, interpretar e refletir sobre relações fânicas que são, em última instância, práticas de consumo, nossa pesquisa reforça como as contribuições foucaultianas são um caminho profícuo aos estudos de Marketing (ver Arnould \& Thompson, 2015). Além disso, o estudo contribui com uma sistematização da genealogia do sujeito ético, método desenvolvido pelo filósofo, como meio para investigar constituições de subjetividades, formulações éticas e conduções de agências morais (Foucault, 2020b).

Reconhecemos, por fim, que nosso estudo se limitou ao fórum mais notório do produto de mídia explorado nesta investigação (i.e., ASolaF): Westeros.org. Essa escolha foi incidental, pois consideramos o meio mais profícuo para observar a relação uma das transmidiações mais ressonantes à cultura pop nos últimos anos. Ainda, consideramos que pesquisas futuras que tratem de transmidiações e o consequente rebu nos fandoms de outros produtos de mídia podem dar continuidade ao que foi apresentado aqui.

\section{AGRADECIMENTOS}

O Conselho Nacional de Desenvolvimento Científico e Tecnológico (CNPq) apoiou a presente pesquisa.

A Coordenação de Aperfeiçoamento de Pessoal de Nível Superior (CAPES) apoia o programa de pós-graduação ao qual os pesquisadores têm vínculo. 


\section{REFERÊNCIAS}

Arnould, E., \& Thompson, C. J. (2015). Introduction: consumer culture theory: Ten years gone (and beyond). Consumer Culture Theory, 17(1), 1-21. doi: 10.1108/So885-211120150000017001

Ashman, R., Patterson, A., \& Brown, S. (2018). 'Don't forget to like, share and subscribe': Digital autopreneurs in a neoliberal world. Journal of Business Research, 92, 474-483. doi: 10.1016/j.jbusres.2018.07.055

Beighton, C. (2017). Groundhog day? Nietzsche, Deleuze and the eternal return of prosumption in lifelong learning. Journal of Consumer Culture, 17(3), 695-712. doi: $10.1177 \% 2 \mathrm{~F}_{14} 69540515623607$

Belk, R. W. (2001). Collecting in a consumer society. New York, USA: Routledge.

Booth, P. (2010). Digital fandom: New media studies. New York, USA: Peter Lang.

Booth, P. (2015). Fans' list-making: memory, influence, and argument in the "event" of fandom. MATRIZes, 9(2), 85-107. doi: 10.11.6o6/issn.1982-816o.v9.i2p.85-108

Booth, P. J. (2018). Framing alterity: Reclaiming fandom's marginality. Transformative Works and Cultures, 28. doi: 10.3983/twc.2018.1420

Chen, Z. T. (2021). Poetic prosumption of animation, comic, game and novel in a post-socialist China: A case of a popular video-sharing social media Bilibili as heterotopia. Journal of Consumer Culture, 21(2), 257-277. doi: $10.1177 \% 2 F_{14} 69540518787574$

Clark, T. (2019, April 18). How 'Game of Thrones' viewership compares with TV's other most-watched shows. Recuperado de https://www.businessinsider.com/game-of-thronescompared-to-most-popular-tv-shows -of-2018-ratings-2019-4

Coskuner-Balli, G. (2020). Citizen-consumers wanted: Revitalizing the American dream in the face of economic recessions, 1981-2012. Journal of Consumer Research, 47(3), 327-349. doi: $10.1093 / \mathrm{jcr} / \mathrm{uczo} 59$

Coulter, N. (2021). "Frappés, friends, and fun": Affective labor and the cultural industry of girlhood. Journal of Consumer Culture, 21(3), 487-500. doi: 10.1177\%2F1469540518806954

Deleuze, G. (1988). Foucault. Minnesota, USA: University of Minnesota Press.

Delwiche, A., \& Henderson, J. (2012). The participatory cultures handbook. New York, USA: Routledge.

Denegri-Knott, J., Nixon, E., \& Abraham, K. (2018). Politicising the study of sustainable living practices. Consumption Markets \& Culture, 21(6), 554-573. doi: 10.1080/10253866.2017.1414048

Fathallah, J. (2015). Statements and silence: Fanfic paratexts for ASOIAF/Game of Thrones. Continuum, 30(1), 75-88. doi: 10.1080/10304312.2015.1099150

Fathallah, J. (2016). 'Except that Joss Whedon is god': Fannish attitudes to statements of author/ity. International Journal of Cultural Studies, 19(4), 459-476. doi: 10.1177\%2F1367877914537589
Foucault, M. (2004). Uma estética da existência. In M. Motta (Org.), Ética, sexualidade e política (Coleção Ditos \& Escritos, pp. 288-293). Rio de Janeiro, RJ: Forense Universitária.

Foucault, M. (2010). A hermenêutica do sujeito: Curso no Collège de France (1981-1982). São Paulo, SP: Martins Fontes.

Foucault, M. (2016). Subjetividade e verdade: Curso no Collège de France (1980-1981). São Paulo, SP: Martins Fontes.

Foucault, M. (2020a). História da sexualidade: A vontade de saber (Vol. 1). São Paulo, SP: Paz e Terra.

Foucault, M. (2020b). História da sexualidade: O uso dos prazeres (Vol. 2). São Paulo, SP: Paz e Terra.

Foucault, M. (2020c). História da sexualidade: 0 cuidado de si (Vol. 3). São Paulo, SP: Paz e Terra.

Fuschillo, G. (2017). Beyond the market: The societal influence of fandoms. Consumer Culture Theory, 18(1), 169-192. doi: 10.1108/So885-211120160000018013

Fyrberg-Yngfalk, A., Cova, B., Pace, S., \& Skålén, P. (2014). Control and power in online consumer tribes: The role of confessions. Consumer Culture Theory, 15(1), 325-350. doi: 10.1108/So8852111(2013)0000015021

Guschwan, M. (2012). Fandom, brandom and the limits of participatory culture. Journal of Consumer Culture, 12(1), 1940. doi: $10.1177 \% 2$ F1469540512438154

Hills, M. (2013). Fiske's 'textual productivity' and digital fandom: Web 2.0 democratization versus fan distinction? Participations: Journal of Audience and Reception Studies, 10(1), 130-153. Recuperado de https://www.participations. org/Volume\%2010/Issue\%201/9\%20Hills\%2010. 1.pdf

Hirschman, E. C., \& Holbrook, M. B. (1982). Hedonic consumption: Emerging concepts, methods and propositions. Journal of Marketing, 46, 92-101. doi: 10.1177\%2Fo02224298204600314

Jantzen, C., Fitchett, J., Østergaard, P., \& Vetner, M. (2012). Just for fun? The emotional regime of experiential consumption. Marketing Theory, 12(2), 137-154. doi: $10.1177 \% 2 \mathrm{~F} 1470593112441565$

Jenkins, H. (2006). Fans, bloggers, and gamers: Exploring participatory culture. New York, USA: NYU Press.

Jenkins, H. (2007). The WOW climax: Tracing the emotional impact of popular culture. New York, USA: NYU Press.

Jenkins, H. (2015). Invasores do texto: Fãs e cultura participativa. Rio de Janeiro, RJ: Marsupial.

Kompare, D. (2018). Fan curators and the gateways into fandom. In M. A. Click \& S. Scott (Eds.), The Routledge Companion to media fandom. New York, USA: Routledge.

Kozinets, R. V. (1999). E-tribalized marketing? the strategic implications of virtual communities of consumption. European Management Journal, 17(3), 252-264. doi: 10.1016/ So263-2373(99)00004-3 
Kozinets, R. V. (2001). Utopian enterprise: Articulating the meanings of Star Trek's culture of consumption. Journal of Consumer Research, 28(1), 67-88. doi: 10.1086/321948

Maas, J. (2019). 'Game of Thrones' ties its own record for most emmys won by a series in a single season. Recuperado de https://www.thewrap.com/game-of-thrones-most-emmyswon-series-single-season-record-emmy-awards/

MacNeill, K. (2017). Torrenting Game of Thrones: So wrong and yet so right. Convergence: The International Journal of Research into New Media Technologies, 23(5), 545-562. doi: $10.1177 \% 2 \mathrm{~F} 1354856516640713$

McCracken, G. (1988). Culture and consumption: New approaches to the symbolic character of consumer goods and activities. Bloomington, USA: Indiana University Press.

Mikkonen, I., \& Bajde, D. (2013). Happy Festivus! Parody as playful consumer resistance. Consumption Markets \& Culture, 16(4), 311-337. doi: 10.1080/10253866.2012.662832

Mikkonen, I., Moisander, J., \& Fırat, A. F. (2011). Cynical identity projects as consumer resistance: The Scrooge as a social critic?. Consumption, Markets and Culture, 14(1), 99-116. doi: 10.1080/10253866.2011.541163

Moura, B. M., \& de Souza-Leão, A. L. M. (2020). Consumption attachments of Brazilian fans of the National Football League: A netnography on Twitter interactions. Innovation \& Management Review, 17(3), 251-266. doi: 10.1108/INMR-02 2019-0015

Ritzer, G. (2014). Prosumption: Evolution, revolution, or eternal return of the same? Journal of Consumer Culture, 14(1), 3-24. doi: $10.1177 \% 2$ F1469540513509641

Ryan, C. (2015). Music fanzine collecting as capital accumulation. Participations: Journal of Audience \& Reception Studies, 12 (2), 238-254. Recuperado de https://www.participations.org/ Volume\%2012/Issue\%202/14.pdf

Sarikakis, K., Krug, C., \& Rodriguez-Amat, J. R. (2017). Defining authorship in user-generated content: Copyright struggles in
The Game of Thrones. New Media \& Society, 19(4), 542-559. doi: $10.1177 \% 2 F_{14} 61444815612446$

Schau, H. J., Muñiz, A. M., \& Arnould, E. J. (2009). How brand community practices create value. Journal of Marketing, 73(5), 30-51. doi: $10.1509 \% 2$ Fjmkg.73.5.30

Schouten, J. W., \& McAlexander, J. H. (1995). Subcultures of consumption: An ethnography of the new bikers. Journal of Consumer Research, 22(1), 43. doi: 10.1086/209434

Souza-Leão, A. L. M. de, \& Moura, B. M. (2018). Temos que pegar todos! Discursos identitários sobre o consumo de Pokemon GO no Brasil. Revista Brasileira de Marketing, 17(6), 895-913. doi: 10.5585 /bjm.v17i6.3830

Spanò, C. (2016). Audience engagement with multi-level fictional universes: The case of Game of Thrones and its Italian fans. Participations: Journal of Audience \& Reception Studies, 13(1), 625-655. Recuperado de https://www.participations.org/ Volume $\% 2013 /$ Issue $\% 201 /$ S3/9.pdf

Thompson, C. J., Henry, P. C., \& Bardhi, F. (2018). Theorizing reactive reflexivity: Lifestyle displacement and discordant performances of taste. Journal of Consumer Research, 45(3), 571-594. doi: 10.1093/jcr/ucy018

Thompson, C. J., \& Kumar, A. (2021). Beyond consumer responsibilization: Slow Food's actually existing neoliberalism. Journal of Consumer Culture, 21(2), 317-336. doi: $10.1177 \% 2 \mathrm{~F} 1469540518818632$

Wells-Lassagne, S. (2013). Prurient pleasures: Adapting fantasy to HBO. Journal of Adaptation in Film \& Performance, 6(3), 415-426. doi: 10.1386/jafp.6.3.415_1

Woodward, S., \& Greasley, A. (2017). Personal collections as material assemblages: A comparison of wardrobes and music collections. Journal of Consumer Culture, 17(3), 659-676. doi: $10.1177 \% 2 \mathrm{~F} 1469540515611202$

Young, H. (2014). Race in online fantasy fandom: Whiteness on Westeros.org. Continuum, 28(5), 737-747. doi: 10.1080/10304312.2014.941331

\section{CONTRIBUIÇÃO DE AUTORIA}

Thiago Ianatoni Camargo trabalhou na conceitualização, abordagem teórica-metodológica e revisão teórica (levantamento de literatura), realizou a coleta e análise de dados e a redação do artigo. André Luiz Maranhão de Souza-Leão trabalhou na conceitualização, abordagem teórica-metodológica e revisão teórica (levantamento de literatura), participou da análise de dados e realizou a revisão final do artigo. Bruno Melo Moura trabalhou na conceitualização e revisão teórica (levantamento de literatura) e participou da redação e revisão final do artigo. 